\title{
Differentially Organized Top-Down Modulation of Prepulse Inhibition of Startle
}

\author{
Yi Du (杜忆), Xihong Wu (吴空宏), and Liang Li (李量) \\ Department of Psychology, Speech and Hearing Research Center, Key Laboratory on Machine Perception (Ministry of Education), Peking University, \\ Beijing 100871, China
}

\begin{abstract}
Prepulse inhibition (PPI) of startle is the suppression of the startle reflex when a weaker sensory stimulus (the prepulse) shortly precedes the startling stimulus. PPI can be attentionally enhanced in both humans and laboratory animals. This study investigated whether the following three forebrain structures, which are critical for initial cortical processing of auditory signals, auditory fear conditioning/ memories, and spatial attention, respectively, play a role in the top-down modulation of PPI in rats: the primary auditory cortex (A1), lateral nucleus of the amygdala (LA), and posterior parietal cortex (PPC). The results show that, under the noise-masking condition, PPI was enhanced by fear conditioning of the prepulse in a prepulse-specific manner, and the conditioning-induced PPI enhancement was further increased by perceptual separation between the conditioned prepulse and the noise masker. Reversibly blocking glutamate receptors in the A1 with $2 \mathrm{~mm}$ kynurenic acid eliminated both the conditioning-induced and perceptual separation-induced PPI enhancements. Blocking the LA eliminated the conditioning-induced but not the perceptual separation-induced PPI enhancement, and blocking the PPC specifically eliminated the perceptual separation-induced PPI enhancement. The two types of PPI enhancements were also eliminated by the extinction manipulation. Thus, the top-down modulation of PPI is differentially organized and depends on operations of various forebrain structures. Due to the fine-tuned modulation by higher-order cognitive processes, functions of PPI can be more flexible to complex environments. The top-down enhancements of PPI in rats are also useful for modeling some mental disorders, such as schizophrenia, attention deficit/hyperactivity disorder, and posttraumatic stress disorder.
\end{abstract}

\section{Introduction}

The startle reflex, the whole-body reflexive response to sudden and intense sensory stimuli (Landis and Hunt, 1939; Koch, 1999; Yeomans et al., 2002), can disrupt cognitive/behavioral performances (Hoffman and Overman, 1971; Foss et al., 1989). Prepulse inhibition (PPI) of startle is the suppression of the startle reflex when a weaker sensory stimulus (the prepulse) shortly precedes the startling stimulus (Hoffman and Searle, 1965; Hoffman and Ison, 1980). According to the "protection of processing" theory (Graham, 1975), receiving a sensory stimulus triggers both the information processing for the stimulus signal and the gating mechanism dampening effects of disruptive inputs, and PPI may provide a protection of the early processing of the prepulse signal from interference. Thus, PPI is generally recognized as an operational measure of sensorimotor gating (Braff and Geyer, 1990; Swerdlow et al., 1991; Cadenhead et al., 1993).

Although the PPI-mediating circuitry resides in the brainstem (Davis and Gendelman, 1977; Fox, 1979; Li and Frost, 2000) (for

\footnotetext{
Received March 14, 2011; revised July 24, 2011; accepted July 29, 2011.

Author contributions: Y.D., X.W., and L.L. designed research; Y.D. performed research; Y.D. and L.L. contributed unpublished reagents/analytic tools; Y.D., X.W., and L.L. analyzed data; Y.D., X.W., and L.L. wrote the paper.

This work was supported by National Natural Science Foundation of China Grant 30950030, "973" National Basic Research Program of China Grant 2009CB320901, Chinese Ministry of Education Grant 20090001110050, and "985" grants from Peking University.

Correspondence should be addressed to Dr. Liang Li, Department of Psychology, Peking University, Beijing 100871, China. E-mail: liangli@pku.edu.cn.

DOI:10.1523/JNEUROSCI.1292-11.2011

Copyright $\odot 2011$ the authors $\quad 0270-6474 / 11 / 3113644-10 \$ 15.00 / 0$
}

review, see Fendt et al., 2001; Li and Yue, 2002), indicating that PPI principally reflects an automatic process at the preattentive stage, PPI can be top-down modulated by either feature-based attention or spatial attention to the prepulse in both humans and rats (for review, see Li et al., 2009). In rats, for instance, when the prepulse is fear conditioned, it draws more attention and the conditioned prepulse-induced PPI is enhanced (Huang et al., 2007; Zou et al., 2007; Li et al., 2008; Du et al., 2009b, 2010; Ishii et al., 2010). Also, a precedence effect-induced perceived spatial separation between the conditioned prepulse and the noise masker further enhances PPI by facilitating spatial attention to the prepulse (Du et al., 2009b, 2010). Clearly, the top-down attentional modulation of PPI contains various components that may involve different forebrain structures. This study investigated whether the following three forebrain structures are involved in the attentional modulation of PPI in rats: the primary auditory cortex (A1), lateral nucleus of the amygdala (LA), and posterior parietal cortex (PPC).

The A1 occupies the initial stage of cortical processing of auditory signals and provides auditory inputs to other cortical or forebrain subcortical regions including the PPC and amygdala (Romanski and LeDoux, 1993; Reep et al., 1994). It also projects directly to the auditory midbrain, such as the inferior colliculus (IC) (Herbert et al., 1991; Druga et al., 1997), which is also a structure in the PPI circuitry (Li et al., 1998a,b). The LA, which is involved in the formation of emotional learning (Romanski and LeDoux, 1992; Pitkänen et al., 1997), storage of fear memories (Blair et al., 2005; Schafe et al., 2005), and attentional bias toward 
the threat (Maren, 2007; Meck and MacDonald, 2007; Cisler and Koster, 2010), also plays a role in affecting PPI (Swerdlow et al., 2001), while the PPC is important in mediating spatial attention shift/orienting in humans (Kim et al., 1999; Yantis et al., 2002; Greenberg et al., 2010) and directed spatial attention in rats (Reep and Corwin, 2009).

\section{Materials and Methods}

Animal preparation. According to the target forebrain structure (A1, LA, or PPC) and the injected agent [the broad-spectrum antagonist of glutamate receptors, kynurenic acid (KYNA), or the vehicle, Locke's solution], 86 young-adult male Sprague Dawley rats (age, 10 weeks; weight, 280-300 g) were randomly assigned to six structure/injection agent groups: (1) Al/KYNA $(n=14),(2)$ Al/vehicle $(n=14)$, (3) LA/KYNA $(n=16),(4) \mathrm{LA} /$ vehicle $(n=14),(5) \mathrm{PPC} / \mathrm{KYNA}(n=14)$, and (6) PPC/vehicle $(n=14)$.

To examine the anatomical specificity of KYNA injection, another 10 rats with KYNA injection within the barrel field of primary somatosensory cortex (S1BF) were used as the anatomical control group. The S1BF is located both on top of the LA area and next to the A1 area.

The surgical procedures were the same as used in our previous studies (Du et al., 2009a,c). Briefly, injection guide cannulae (C317G guide cannula; Plastics One) were bilaterally implanted into one of the four forebrain structures in each of the $10 \%$ chloral hydrateanesthetized ( $400 \mathrm{mg} / \mathrm{kg}$, i.p.) rats. Referenced to bregma, the stereotaxic coordinates of the structures were the following: (1) Al: anteroposterior, $-4.6 \mathrm{~mm}$; mediolateral, $\pm 6.5 \mathrm{~mm}$; depth, $-4.2 \mathrm{~mm}$; (2) LA: anteroposterior, $-3.1 \mathrm{~mm}$; mediolateral, $\pm 5.2 \mathrm{~mm}$; depth, -7.8 $\mathrm{mm}$; (3) PPC: anteroposterior, $-4.4 \mathrm{~mm}$; mediolateral, $\pm 3.1 \mathrm{~mm}$; depth, $-1.6 \mathrm{~mm}$ (Fox et al., 2003); (4) S1BF: anteroposterior, $-3.1 \mathrm{~mm}$; mediolateral, $\pm 5 \mathrm{~mm}$; depth, $-2.5 \mathrm{~mm}$.

Rats were given 1 week for recovery from surgery in a room with the temperature of $24 \pm 2{ }^{\circ} \mathrm{C}$ and a $12 \mathrm{~h}$ light/dark cycle, with food and water available ad libitum. These rats were treated in accordance with the Guidelines of the Beijing Laboratory Animal Center, and the Policies on the Use of Animals and Humans in Neuroscience Research approved by the Society for Neuroscience (2006).

Stimuli and apparatus. The apparatus for PPI testing have been described in detail in our previous reports (Du et al., 2009b, 2010). Briefly, the rat's whole-body startle reflex, which was induced by an intense $10 \mathrm{~ms}$ broadband noise burst $(0-10 \mathrm{kHz}, 100 \mathrm{~dB}$ SPL) delivered by a loudspeaker above the rat's head, was measured by a custom-made electrical scale (National Key Laboratory on Machine Perception, Peking University) in a soundproof chamber. Beginning with the onset of the startling stimulus, electrical voltage signals were collected and sampled (at a frequency of $16 \mathrm{kHz}$ ) for a sufficiently long time $(500 \mathrm{~ms})$. Since a distinct waveform complex of the startle response could be reliably induced by the startling stimulus [Zou et al. (2007), their Fig. 2], in a trial, the peak-to-peak amplitude between the primary peak component (with the latency mainly between 15 and $20 \mathrm{~ms}$ ) and the subsequent peak component (with the latency of mainly between 20 and $25 \mathrm{~ms}$ ) were digitized and measured. The prepulse stimulus was delivered by two spatially separated (i.e., left and right) loudspeakers in the frontal field with a $100^{\circ}$ separation angle and $52 \mathrm{~cm}$ away from the rat's head position.

The prepulse, which started $100 \mathrm{~ms}$ before the startling pulse, was a $50 \mathrm{~ms}$ lower-frequency-harmonic $(1.3,2.6$, and $3.9 \mathrm{kHz})$ or higherfrequency-harmonic $(2.3,4.6$, and $6.9 \mathrm{kHz})$ tone complex. Each of the two prepulse signals was digitally generated by MATLAB software and converted by a custom-developed sound delivery system (National Key Laboratory on Machine Perception, Peking University) with the $16 \mathrm{kHz}$ sampling rate and 16 bit resolution. Sound levels were calibrated by a sound level meter (Brüel \& Kjær; type 2230) whose microphone was placed at the central location of the rat's head when the rat was absent, using a "Fast" /"Peak" meter response. The single-source sound level of the prepulse for each of the two horizontal loudspeakers was fixed at 60 dB SPL.

Procedures. After 1 week of recovery from surgery, each rat went through the $6 \mathrm{~d}$ testing procedure. For the first 3 successive days, the rat was placed into the restraining cage (Zou et al., 2007), whose dimensions matched the size of the rat, and the rat could not reorient their body position. For $30 \mathrm{~min}$ on each of the $3 \mathrm{~d}$, the rat was exposed to a broadband noise ( $60 \mathrm{~dB}$ SPL), which was continuously presented by each of the two horizontal loudspeakers. Neither the prepulse nor the startling noise was presented. This procedure was to adapt the rat to the restraining cage and testing chamber.

On the fourth day, startle responses before conditioning (procedure stage BC) was measured. The rat was placed in the restraining cage for 5 min, receiving 10 presentations of startling stimulus without prepulse presentation on the broadband-noise background whose intensity was $60 \mathrm{~dB}$ SPL. The interval between startling stimuli varied between 25 and $35 \mathrm{~s}$ (mean, $30 \mathrm{~s}$ ). Then the two-session PPI testing was conducted with the two prepulse stimuli being randomly and evenly presented in each session (i.e., the lower- and higher-frequency prepulse stimuli were used in each session). The prepulse was presented from each of the two horizontal loudspeakers with the inter-loudspeaker onset delay being either $+1 \mathrm{~ms}$ (left leading) or $-1 \mathrm{~ms}$ (right leading) in each of the two testing sessions. Due to the precedence effect (Wallach et al., 1949; Litovsky et al., 1999; Li and Yue, 2002), a type of perceptual fusion of correlated leading and lagging sounds based on the attribute-capturing process $(\mathrm{Li}$ et al., 2005; Huang et al., 2011), a single fused prepulse image would be perceived at the left loudspeaker in some trials (when the left loudspeaker led) and at the right loudspeaker in other trials (when the right loudspeaker led). In addition to the prepulse, a broadband noise $(0-10 \mathrm{kHz}$, $60 \mathrm{~dB}$ SPL) was continuously delivered from each of the two horizontal loudspeakers as the masker. The inter-loudspeaker onset delay for the masker was $+1 \mathrm{~ms}$ in one session and $-1 \mathrm{~ms}$ in the other session, leading to a fused continuous noise masker image at the left loudspeaker in one session and at the right loudspeaker in the other session. Thus, two types of perceived spatial relationships between the prepulse and the masker were created in each session: perceptual separation (when prepulse and masker had different leading loudspeakers) and perceptual colocation (when prepulse and masker shared the same leading loudspeaker). Note that a change between the precedence effect-based perceived spatial separation and colocation does not affect the impact of bottom-up sensory inputs but facilitates selective spatial attention to the attended signal ( $\mathrm{Li}$ et al., 2004).

In a testing trial, the startling noise burst started $50 \mathrm{~ms}$ after the offset of the prepulse, making the interstimulus onset interval $100 \mathrm{~ms}(50+50$ $\mathrm{ms}$ ). Then a new trial started $\sim 30 \mathrm{~s}$ (varying from 25 to $35 \mathrm{~s}$ ) after the offset of the prepulse. In each testing session, 10 trials were assigned to the condition of perceptual spatial separation ( 5 trials for each of the two prepulse stimuli), 10 trials were assigned to the condition of perceptual colocation ( 5 trials for each of the two prepulse stimuli), and 5 trials were assigned to the no-prepulse (startling stimulus only) condition.

Then, on the same day, after the PPI testing, rats underwent both the manipulation of fear conditioning and the manipulation of conditioning control (so simply called the conditioning/conditioning-control manipulation). The conditioned stimulus (CS) was the prepulse stimulus delivered by each of the two horizontal loudspeakers with balanced left-right leading, and the unconditioned stimulus (US) was $6 \mathrm{~mA}$ rectangular-pulse (duration, $3 \mathrm{~ms}$ ) footshock using Grass S-88 stimulator (Grass) (Du et al., 2009b, 2010). For each rat, during the fear-conditioning manipulation, 10 temporally synchronized (paired) combinations of the footshock (US) and one of the prepulse stimuli (CS) were presented every $30 \mathrm{~s}$ (US started 3 $\mathrm{ms}$ before CS ending, and coterminated with CS). During the conditioning-control manipulation, 10 temporally random (unpaired) combinations of the footshock and the other prepulse were presented every $30 \mathrm{~s}$. In each group, one-half of the rats received fear conditioning of the lower-frequency prepulse and conditioning control of the higherfrequency prepulse, and the other one-half of the rats received the contrary manipulations.

On the fifth day ( $24 \mathrm{~h}$ after the conditioning/conditioning-control manipulation), PPI after conditioning (procedure stage AC) was measured with the procedure described above. Note that both the conditioned prepulse and the conditioning-control prepulse were always presented in each of the two testing sessions. Then, either the KYNA (2 mм in Locke's solution; Sigma-Aldrich) or Locke's solution was injected 
slowly into bilateral A1 (2.0 $\mu$ l on each side), LA (1.0 $\mu$ l on each side), PPC $(2.0 \mu \mathrm{l}$ on each side), or S1BF (2.0 $\mu$ l on each side) over a period of $\sim 1$ min. Drug administration was made through the guide cannula, which was connected to a $5.0 \mu \mathrm{l}$ microsyringe via polyethylene tubing (inner diameter, $0.38 \mathrm{~mm}$; outer diameter, $1.09 \mathrm{~mm}$; Clay Adams, division of BD Biosciences). PPI after injection (procedure stage AI) was tested 15 min after the injection. Since the blocking effect of KYNA is reversible (Li and Kelly, 1992; Malmierca et al., 2003), PPI testing was conducted again $2 \mathrm{~h}$ after the injection of KYNA when the injected structure recovered from blocking (procedure stage AR).

On the sixth day, all rats underwent the manipulation of fear extinction. Without pairing the US, the conditioned prepulse was presented 60 times and the conditioning-control prepulse was presented 20 times with the interstimulus interval of $30 \mathrm{~s}$. For each rat, the total 80 prepulse presentations ( 60 for CS and 20 for CS control) were evenly divided into four extinction sessions with the intersession interval of $10 \mathrm{~min}$. After the extinction manipulation, PPI was measured again (procedure stage $\mathrm{AE}$ ).

Data analyses. The amount of PPI was calculated with the following generally used formula: PPI $=$ (amplitude to startling sound alone - amplitude to startling sound preceded by prepulse) $/($ amplitude to startling sound alone).

Since in each group, one-half of the rats were fear conditioned with the lower-frequency prepulse (when the higher-frequency prepulse was the conditioning-control stimulus) and the other one-half of the rats were fear conditioned with the higherfrequency prepulse (when the lower-frequency prepulse was conditioning-control stimulus), PPI values were averaged over the two subgroups after normalization. PPI values for each individual rat were normalized relative to the PPI value before the conditioning/ conditioning-control manipulation (procedure stage $\mathrm{BC}$ ) under prepulse/masker colocation condition. Mixed and within-subject repeatedmeasures ANOVAs followed by Bonferroni's pairwise comparisons (for comparisons between procedure stages) and paired $t$ tests (for comparisons between perceived colocation and spatial separation) were performed using SPSS 13.0 software. The null-hypothesis rejection level was set at 0.05 .

Histology. When all recordings were finished, rats were killed with an overdose of chloral hydrate. Lesion marks were made via the cannula by an anodal DC current (500 $\mu \mathrm{A}$ for $10 \mathrm{~s}$ ). Brains were stored in $10 \%$ formalin with $30 \%$ sucrose, and then sectioned at $50 \mu \mathrm{m}$ in the frontal plane in a cryostat $\left(-20^{\circ} \mathrm{C}\right)$. Sections were examined to determine locations of injection cannulae.

\section{Results}

\section{Histology}

According to histological examination (Fig. 1), injection cannulae were precisely located within left A1 area in 13 rats and right $\mathrm{A} 1$ area in 12 rats in the A1/KYNA group (filled circle); within left $\mathrm{A} 1$ area in 12 rats and right $\mathrm{A} 1$ area in 13 rats in the $\mathrm{Al} /$ vehicle group (open circle); within left LA area in 14 rats and right LA area in 12 rats in the LA/KYNA group (filled circle); within left LA area in 12 rats and right LA area in 13 rats in the LA/vehicle group (open circle); within left PPC area in 13 rats and right PPC area in 13 rats in the PPC/KYNA group (filled circle); within left PPC area in 12 rats and right PPC area in 12 rats in the PPC/vehicle

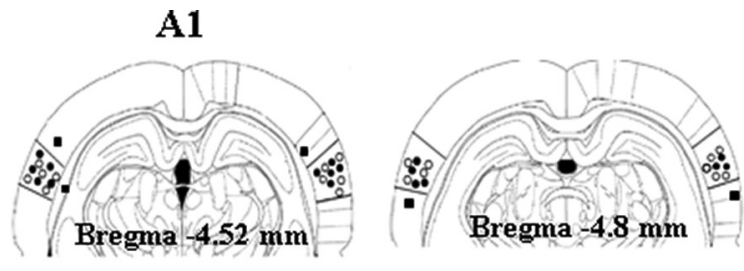

LA
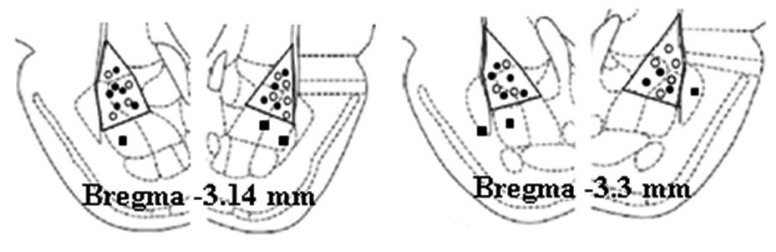

PPC
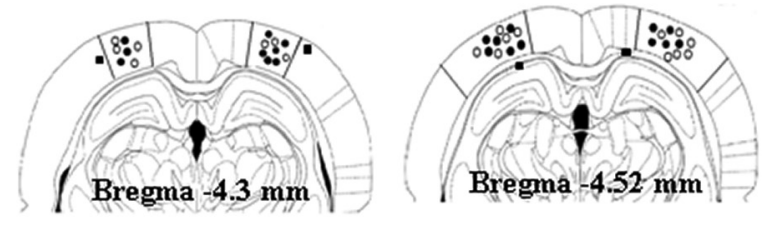

S1BF
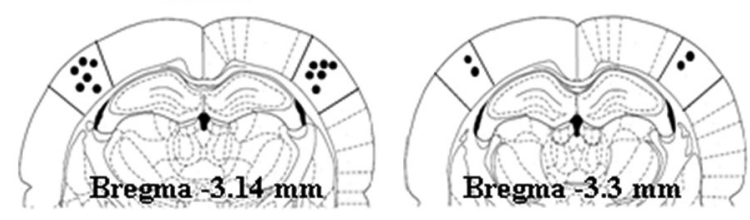

Figure 1. Histological locations of injection cannulae in all 96 rats. Correct locations of cannulae in KYNA groups are labeled by filled circles and in vehicle control groups by open circles. Misplaced cannulae are labeled by filled squares.

group (open circle); within left S1BF area in 10 rats and right $\mathrm{S} 1 \mathrm{BF}$ area in 10 rats in the S1BF/KYNA group.

Rats with unilateral or bilateral misplaced injection cannulae (filled square) were removed from data analyses. Thus, descriptions and statistical analyses here were based on the data from 12 rats in each of six groups (A1/KYNA, A1/vehicle, LA/KYNA, LA/ vehicle, $\mathrm{PPC} / \mathrm{KYNA}$, and $\mathrm{PPC} /$ vehicle) and 10 rats in S1BF/ KYNA group.

\section{Responses to the startling stimulus alone}

Table 1 shows the group mean amplitude of startle response to the startling stimulus alone (when the prepulse was not presented) in each of the rat groups. The baseline startle amplitude significantly increased after the conditioning/conditioningcontrol manipulation (all $p<0.05$, by within-subject repeatedmeasures ANOVA and pairwise comparisons) and reduced to the level at the procedure stage $\mathrm{BC}$ after fear extinction. Injection of either KYNA or Locke's solution into one of the four brain structures did not significantly influence the startle amplitude to the startling stimulus alone (all $p>0.05$ ).

\section{Baseline PPI}

In this study, two types of tone complexes (lower-frequency and higher-frequency ones) were used as the prepulse stimuli. Table 2 shows the unnormalized PPI values obtained at the procedure stage $\mathrm{BC}$ (before the conditioning/conditioning-control manipulation) under prepulse/masker colocation condition for all the rat groups. In each group, the values of PPI induced by the lowerfrequency prepulse and those by the higher-frequency prepulse did not significantly differ (all $p>0.05$ by paired $t$ tests). 
Table 1. Startle amplitudes to the startling stimulus alone

\begin{tabular}{|c|c|c|c|c|c|}
\hline \multirow[b]{2}{*}{ Groups } & \multicolumn{5}{|c|}{ Amplitude in the device scale unit } \\
\hline & $\begin{array}{l}\text { Before } \\
\text { conditioning }\end{array}$ & $\begin{array}{l}\text { After } \\
\text { conditioning }\end{array}$ & $\begin{array}{l}\text { After } \\
\text { injection }\end{array}$ & $\begin{array}{l}\text { After } \\
\text { recovery }\end{array}$ & $\begin{array}{l}\text { After } \\
\text { extinction }\end{array}$ \\
\hline A1/KYNA $(n=12)$ & \multicolumn{3}{|c|}{$1425 \pm 2811640 \pm 2991662 \pm 258$} & $1644 \pm 296$ & $1400 \pm 354$ \\
\hline A1/vehicle $(n=12)$ & $1486 \pm 246$ & $1662 \pm 258$ & $1720 \pm 251$ & N/A & $1516 \pm 187$ \\
\hline LA/KYNA $(n=12)$ & $1104 \pm 466$ & $1336 \pm 537$ & $1354 \pm 571$ & $1267 \pm 535$ & $1055 \pm 561$ \\
\hline LA/vehicle ( $n=12$ ) & $1207 \pm 424$ & $1400 \pm 438$ & $1432 \pm 423$ & N/A & $1267 \pm 456$ \\
\hline PPC/KYNA $(n=12)$ & $1346 \pm 355$ & $1541 \pm 379$ & $1598 \pm 406$ & $1564 \pm 405$ & $1355 \pm 460$ \\
\hline $\mathrm{PPC} /$ vehicle $(n=12)$ & $1290 \pm 415$ & $1449 \pm 413$ & $1479 \pm 426$ & $\mathrm{~N} / \mathrm{A}$ & $1268 \pm 506$ \\
\hline S1BF/KYNA $(n=10)$ & $1109 \pm 316$ & $1252 \pm 433$ & $1286 \pm 220$ & $1268 \pm 390$ & $997 \pm 212$ \\
\hline \multicolumn{6}{|l|}{ Values represent mean $\pm S D$} \\
\hline \multicolumn{6}{|c|}{$\begin{array}{l}\text { Table 2. Group mean baseline PPI values (under perceived prepulse/masker } \\
\text { colocation and before the conditioning/conditioning-control manipulation) }\end{array}$} \\
\hline Groups & & \multicolumn{2}{|c|}{$\begin{array}{l}\text { Lower-frequency } \\
\text { prepulse (\%) }\end{array}$} & \multicolumn{2}{|c|}{$\begin{array}{l}\text { Higher-frequency } \\
\text { prepulse }(\%)\end{array}$} \\
\hline A1/KYNA $(n=12)$ & & \multicolumn{2}{|l|}{$31.7 \pm 7.1$} & \multicolumn{2}{|c|}{$31.5 \pm 8.9$} \\
\hline A1/vehicle $(n=12)$ & & \multicolumn{2}{|c|}{$32.7 \pm 9.4$} & \multicolumn{2}{|c|}{$32.8 \pm 11.1$} \\
\hline LA/KYNA $(n=12)$ & & \multicolumn{2}{|c|}{$34.6 \pm 12.2$} & \multicolumn{2}{|c|}{$34.6 \pm 11.9$} \\
\hline LA/vehicle $(n=12)$ & & \multicolumn{2}{|c|}{$36.6 \pm 17.4$} & \multicolumn{2}{|c|}{$36.4 \pm 15.7$} \\
\hline PPC/KYNA $(n=12)$ & & \multicolumn{2}{|c|}{$31.2 \pm 7.5$} & \multicolumn{2}{|c|}{$30.5 \pm 7.9$} \\
\hline $\mathrm{PPC} /$ vehicle $(n=12)$ & & \multicolumn{2}{|c|}{$34.4 \pm 7.0$} & 32.0 & $0 \pm 7.8$ \\
\hline S1BF/KYNA $(n=10)$ & & $36.0 \pm 7.4$ & & & $9 \pm 7.8$ \\
\hline
\end{tabular}

Values represent mean $\pm S D$.

Effects of KYNA injection on PPI induced by conditioned prepulse

Figure 2 shows the results of PPI for rat groups with injection of KYNA (left panels) or Locke's solution (right panels) into the A1 (top panels), LA (middle panels), and PPC (bottom panels), respectively, during different procedure stages. To emphasize the most important results of the present study, we first summarize the effects of injecting KYNA into one of the three brain structures when the prepulse was the conditioned tone complex (Fig. 2a,c,e).

For each of the three rat groups with KYNA injection (A1/ KYNA, LA/KYNA, PPC/KYNA), there is no evidence in Figure 2 to suggest that at procedure stage $\mathrm{BC}$ the perceived spatial separation between the prepulse and masker enhanced PPI. However, there is evidence to suggest that, when the prepulse became conditioned (procedure stage AC), PPI was remarkably enhanced, and the enhancement was further increased by the perceived spatial separation. Then, injection of KYNA markedly reduced the two PPI enhancements (procedure stage AI) and the degree of the reductions was brain structure dependent. Also, the injection effects disappeared $2 \mathrm{~h}$ after the injection (procedure stage $\mathrm{AR}$ ). Finally, following the extinction manipulation (procedure stage $\mathrm{AE}$ ), the PPI level returned to that at procedure stage $\mathrm{BC}$.

Statistical tests were applied to examine the observations. For each of the three groups, a 5 (procedure stage: $\mathrm{BC}, \mathrm{AC}, \mathrm{AI}, \mathrm{AR}$, $\mathrm{AE}) \times 2$ (perceived spatial relationship, simply called separation type: colocation, separation) within-subject repeated-measures ANOVA shows that the interaction between the two factors was significant (all $F_{(4,44)}>23 ; p<0.001$ ). Pairwise comparisons (for comparisons between procedure stages) and paired $t$ tests (for comparisons between separation types) show that (1) at procedure stage $\mathrm{BC}$, the effect of separation type on PPI was not significant (all $\left.t_{(11)}<1.7 ; p>0.05\right)$; (2) the PPI level at procedure stage AC was significantly larger than that at procedure stage $\mathrm{BC}(p<$ 0.01 ); (3) at procedure stage AC, the effect of separation type on PPI was significant (all $t_{(11)}>7.4 ; p<0.001$ ).

Following injection of KYNA into one of the three brain structures, both the conditioning-induced and separation-induced

\section{KYNA Groups Vehicle Groups} Primary Auditory Cortex
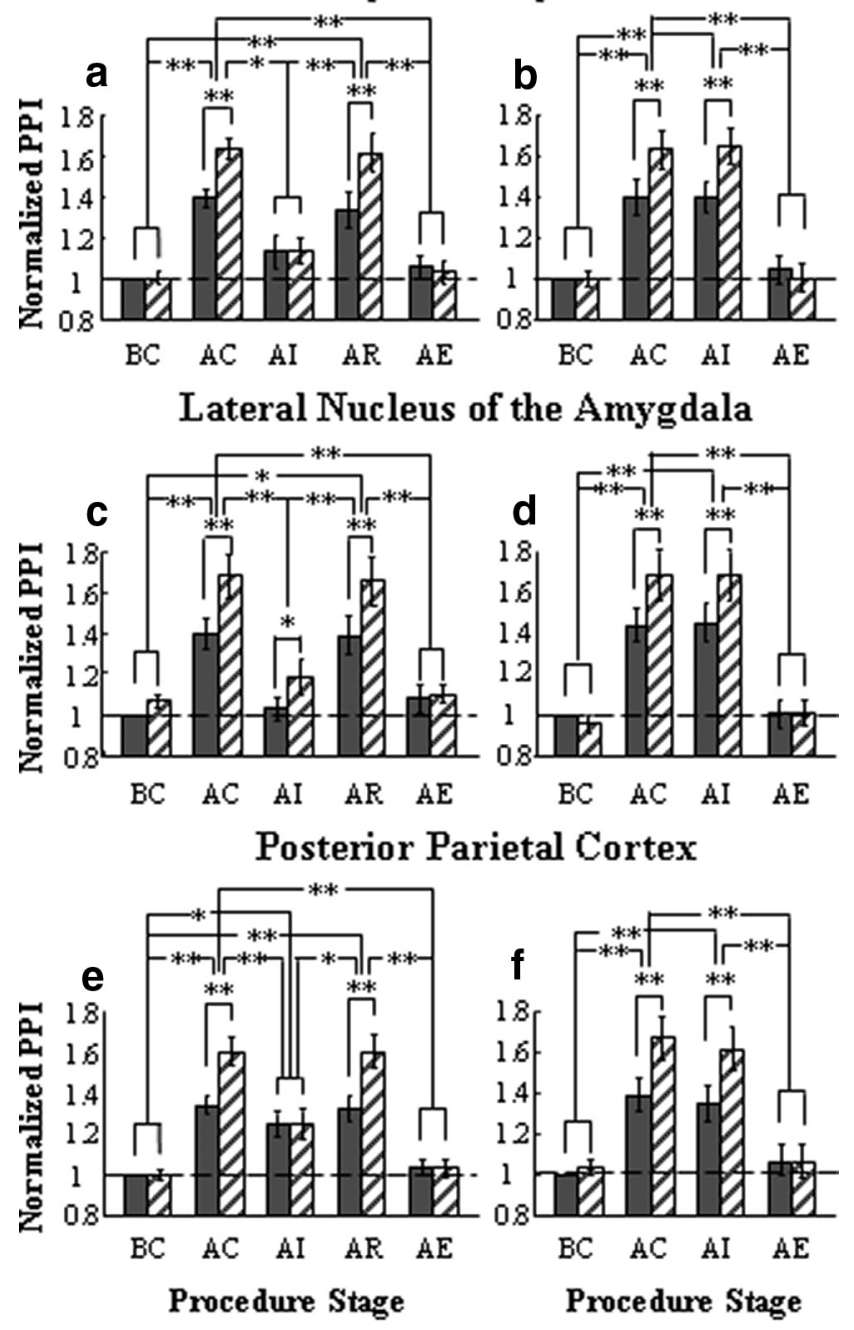

$\square$ co-location $Z 7$ separation

Figure 2. Normalized PPI induced by the conditioned prepulse at different procedure stages in A1/KYNA group $(n=12)(\boldsymbol{a})$, A1/vehicle group $(n=12)(\boldsymbol{b})$, LA/KYNA group $(n=12)(\boldsymbol{c})$, LA/vehicle group $(n=12)(\boldsymbol{d}), \operatorname{PPC} / K Y N A$ group $(n=12)(\boldsymbol{e})$, and PPC/vehicle group $(n=12)$ $(\boldsymbol{f})$. The filled bars represent the conditions when the prepulse was perceptually colocated with the noise masker, while the diagonal bars represent the conditions when the prepulse was perceptually separated with the noise masker. $B C$, Before conditioning; $A C$, after conditioning; $A l$, after injection; $A R$, after recovery; $A E$, after extinction. In this and the next figures, all the PPI values were normalized relative to the value at the procedure stage $B C$ and under the prepulse/ masker colocation condition. Error bars represent the SEM. ${ }^{* *} p<0.01$ and ${ }^{*} p<0.05$ (by repeated-measures ANOVA, Bonferroni's pairwise comparisons, and paired $t$ tests).

PPI enhancements were changed and the changes depended on the injected brain structure (see below).

Effects of blocking the A1 on PPI induced by conditioned prepulse

Following injection of KYNA into the A1 (Fig. $2 a$, procedure stage AI), perceived spatial separation-induced PPI enhancements disappeared (colocation vs separation, $t_{(11)}=0.335, p>$ $0.05)$. Also, the PPI level at procedure stage AI became significantly smaller than that at procedure stage $\mathrm{AC}(p<0.05)$, but not significantly different from that at procedure stage $\mathrm{BC}(p>0.05)$. Two hours after the injection (procedure stage AR), the PPI level 
recovered to that at procedure stage $\mathrm{AC}(p>0.05)$ and became significantly larger than that at procedure stage AI $(p<0.01)$. Moreover, the significant effect of separation type reappeared $\left(t_{(11)}=8.152 ; p<0.001\right)$. After the extinction manipulation, the PPI level returned to that at procedure stage BC $(p>0.05)$, and the effect of separation type became not significant $\left(t_{(11)}=1.616\right.$; $p>0.05)$. Thus, blocking the A1 completely abolished both the conditioning-induced PPI enhancement and the perceptual separation-induced PPI enhancement.

Effects of blocking the LA on PPI induced by conditioned prepulse

Following injection of KYNA into the LA (Fig. $2 c$, procedure stage AI), the PPI level became significantly reduced compared with that at procedure stage AC $(p<0.01)$. More specifically, the group mean reduction was $26.3 \%$ under the colocation condition and $30.0 \%$ under the separation condition, leading to that the PPI level returned to that at procedure stage $\mathrm{BC}(p>0.05)$. However, the effect of separation type on PPI was still significant $\left(_{(11)}=\right.$ 2.282; $p<0.05$ ). Two hours after the injection (procedure stage $\mathrm{AR})$, the PPI level was significantly larger than that at procedure stage AI $(p<0.01)$ and became not significantly different from that at procedure stage $\mathrm{AC}(p>0.05)$. Also, the effect of separation type remained significant $\left(t_{(11)}=7.233 ; p<0.001\right)$. At procedure stage AE, the PPI level returned to that at procedure stage BC $(p>0.05)$, and the effect of separation type became not significant $\left(t_{(11)}=0.788 ; p>0.05\right)$. Thus, blocking the LA abolished the conditioning-induced PPI enhancement but not the perceptual separation-induced PPI enhancement.

\section{Effects of blocking the PPC on PPI induced by conditioned prepulse}

Following injection of KYNA into the PPC (Fig. $2 e$, procedure stage AI), although the PPI level became significantly smaller than that at procedure stage $\mathrm{AC}(p<0.01)$, it was still significantly larger than that at procedure stage $\mathrm{BC}(p<0.05)$. Also, the effect of separation type on PPI became not significant $\left(t_{(11)}=\right.$ $0.029 ; p>0.05$ ). Two hours after the injection (procedure stage $\mathrm{AR})$, the PPI level was significantly larger than that at procedure stage AI $(p<0.05)$ and became not significantly different from that at procedure stage AC $(p>0.05)$. Also, the effect of separation became significant again $\left(t_{(11)}=9.973 ; p<0.001\right)$. At procedure stage $\mathrm{AE}$, the PPI level returned to that at procedure stage $\mathrm{BC}(p>0.05)$ and the effect of separation type became not significant $\left(t_{(11)}=0.150 ; p>0.05\right)$. Thus, blocking the PPC abolished the perceptual separation-induced PPI enhancement but not the conditioning-induced PPI enhancement.

\section{Effects of vehicle injection on PPI induced by} conditioned prepulse

Figure $2, b, d$, and $f$, show the PPI levels for rat groups with injection of Locke's solution into the A1, LA, or PPC at different procedure stages when the prepulse was the conditioned tone complex. Briefly, the only difference in PPI between the vehicle injection groups and the KYNA injection groups was that, in each of the three vehicle groups, the injection did not significantly change either the conditioning-induced PPI enhancement (procedure stage AI vs procedure stage AC, $p>0.05$ ) or the separation effect (at procedure stage AI, PPI under separation condition was still larger than that under colocation condition; all $t_{(11)}>$ $4.5, p<0.01)$.

\section{KYNA Groups Vehicle Groups Primary Auditory Cortex}
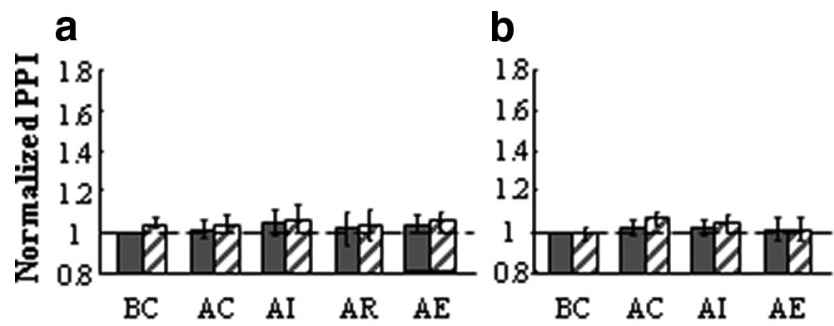

Lateral Nucleus of the Amygdala
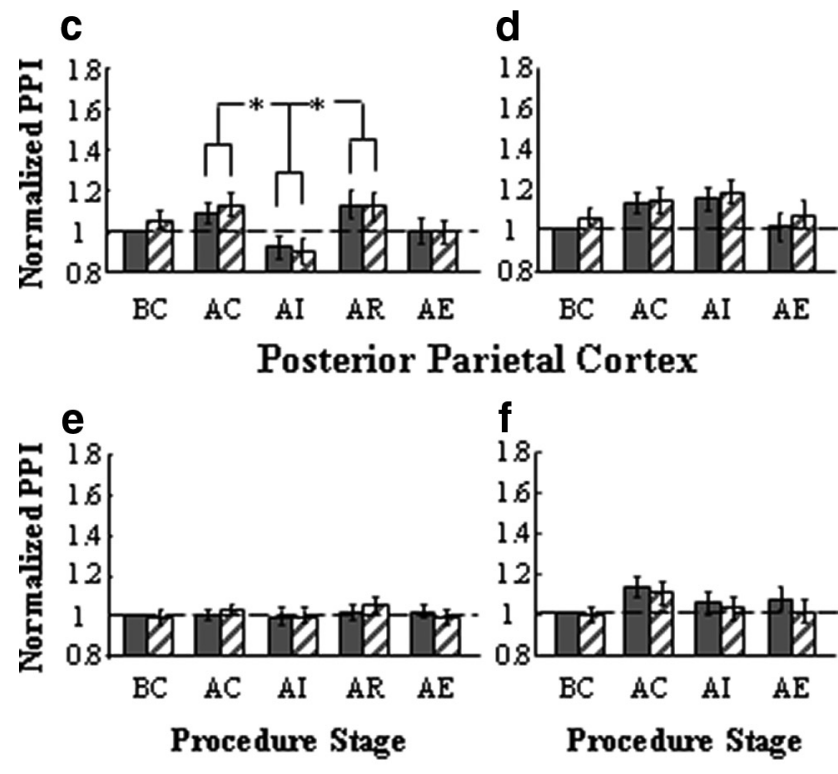

\section{a co-location $\square$ separation}

Figure 3. Normalized PPI elicited by the conditioning-control prepulse at different procedure stages in A1/KYNA group ( $n=12)(\boldsymbol{a})$, A1/vehicle group $(n=12)(\boldsymbol{b})$, LA/KYNA group $(n=12)(\boldsymbol{c})$, LA/vehicle group $(n=12)(\boldsymbol{d}), \mathrm{PPC} / \mathrm{KYNA}$ group $(n=12)(\boldsymbol{e})$, and PPC/vehicle group $(n=12)(\boldsymbol{f})$. See Figure 2 legend for the explanation of symbols and abbreviations. ${ }^{*} p<$ 0.05 (by repeated-measures ANOVA and Bonferroni's pairwise comparisons).

\section{PPI induced by conditioning-control prepulse}

Figure 3 shows the PPI levels for rat groups with injection of either KYNA (left panels) or Locke's solution (right panels) into the A1, LA, or PPC at different procedure stages when the prepulse was the conditioning-control tone complex.

For the three groups with the injection of KYNA, the conditioning-control manipulation did not cause any marked effects on PPI. For either the A1/KYNA group (Fig. $3 a$ ) or the PPC/KYNA group (Fig. 3e), injection of KYNA did not change PPI induced by the conditioning-control prepulse. A 5 (procedure stage: $\mathrm{BC}, \mathrm{AC}, \mathrm{AI}, \mathrm{AR}, \mathrm{AE}) \times 2$ (separation type) withinsubject ANOVA confirms that the main effect of procedure stage and the main effect of separation type were not significant (all $F<4.7 ; p>0.05$ ), and the interaction between the two factors was not significant (both $F_{(4,44)}<1.6 ; p>0.05$ ).

However, for the LA/KYNA group, injection of KYNA into the LA reduced the PPI level by $15.7 \%$ in the group mean under the colocation condition and $19.7 \%$ under the separation condition, and this PPI reduction disappeared $2 \mathrm{~h}$ after the injection (Fig. $3 c$ ). A 5 (procedure stage) $\times 2$ (separation type) within-subject ANOVA shows that the main effect of procedure stage was signifi- 


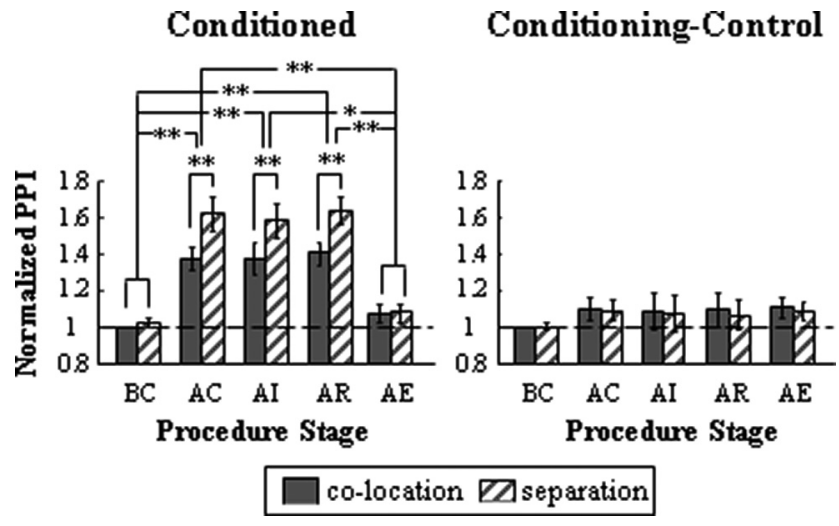

Figure 4. Normalized PPI elicited by the conditioned prepulse (left panel) and conditioningcontrol prepulse (right panel) at different procedure stages in the S1BF/KYNA group $(n=10)$. See Figure 2 legend for the explanation of symbols and abbreviations. ${ }^{* *} p<0.010$ and ${ }^{*} p<$ 0.05 (by repeated-measures ANOVA, Bonferroni's pairwise comparisons, and paired $t$ tests).

cant $\left(F_{(4,44)}=3.459 ; p<0.05\right)$, the main effect of separation type was not significant $\left(F_{(1,11)}<0.4 ; p>0.05\right)$, and the interaction between the two factors was not significant $\left(F_{(4,44)}<1.0 ; p>0.05\right)$. Pairwise comparisons show that the PPI level at procedure stage AI was significantly smaller than those at procedure stage AC and procedure stage AR $(p<0.05)$.

Meanwhile, neither the conditioning-control manipulation nor injection of Locke's solution affected PPI in each of the three vehicle control groups (A1/vehicle, LA/vehicle, PPC/vehicle). For each group, a 4 (procedure stage: $\mathrm{BC}, \mathrm{AC}, \mathrm{AI}, \mathrm{AE}) \times 2$ (separation type) within-subject ANOVA confirms that either the main effect of procedure stage or the main effect of separation type was not significant (all $F<4.4 ; p>0.05$ ), and the interaction between the two factors was not significant (all $F<1.4 ; p>0.05$ ).

\section{Effects of blocking the S1BF area on PPI induced by conditioned prepulse}

To examine the anatomical specificity of KYNA injection, PPI was tested in 10 rats with KYNA injection into the S1BF area. As Figure 4 shows, bilateral injection of $2 \mu \mathrm{l}$ of KYNA into the S1BF did not significantly affect PPI under either the colocation or the separation condition, when PPI was induced by either the conditioned prepulse or the conditioning-control prepulse (all $p>$ $0.05)$. Thus, the results confirm the anatomical specificity of the blocking effect of KYNA injection.

\section{Discussion}

Two types of top-down enhancements of PPI

The PPI level depends on the salience and processing depth of the prepulse signal (Carlson and Willott, 1996; Ison et al., 1998; Röskam and Koch, 2006; Franklin et al., 2007; Huang et al., 2007; Zou et al., 2007; Li et al., 2008; Du et al., 2009b, 2010). Fear conditioning of the prepulse specifically improves the ecological salience of the conditioned prepulse stimulus and facilitates rats' attention to the "selected" prepulse, thereby enhancing PPI as revealed in this and previous studies (Huang et al., 2007; Zou et al., 2007; Li et al., 2008; Du et al., 2009b, 2010; Ishii et al., 2010). Also, the precedence effect-based perceived spatial separation between the masker and the conditioned prepulse (but not the conditioning-control prepulse) causes a further enhancement of PPI as revealed by this and previous studies (Du et al., 2009b, 2010). More importantly, this study for the first time reveals that the three forebrain structures, A1, LA, and PPC, contribute to the two types of PPI enhancements differently.

\section{Contributions of the A1}

Synthesized and released within the CNS, KYNA is the only known endogenous antagonist of excitatory amino acid (glutamate) receptors (Swartz et al., 1990). Using KYNA as a blocking means has several advantages over other chemically or physically blocking methods (such as local injection of anesthetics to block sodium channels and local cooling): First, due to its broadspectrum nature in blocking glutamate receptors, KYNA blocks both non-NMDA and NMDA receptors (Stone and Connick, 1985; Kessler et al., 1989; Thomson et al., 1989). Thus, KYNA generally blocks glutamate receptor-mediated excitatory inputs to the injected area, reducing excitation of neurons in the area. In addition, since KYNA does not influence axonal conduction, activity of unrelated axons passing the injected area is not affected. Finally, the blocking effect of KYNA is reversible (Li and Kelly, 1992; Malmierca et al., 2003).

The results of this study show that both the conditioninginduced and perceptual separation-induced PPI enhancements were completely eliminated by reversibly blocking excitatory glutamate receptors in the A1 with KYNA, suggesting that the initial cortical processing of the conditioned-prepulse signals is critical for the formation of the two types of top-down enhancements of PPI.

It is known that the A1 is the primary cortical source for providing auditory signals to other cortical regions and forebrain subcortical structures including the PPC and amygdala (Romanski and LeDoux, 1993; Reep et al., 1994) (for review, see Wang et al., 2008). If some of the forebrain structures receiving auditory signals from the A1 are closely involved in the conditioninginduced and/or perceptual separation-induced PPI enhancements, blocking the A1 diminishes acoustically driven activities of these forebrain structures and eliminates the top-down modulations. In addition, by measuring regional cerebral blood flows (O'Leary et al., 1997; Hugdahl et al., 2000), neuromagnetic fields (Fujiwara et al., 1998; Poghosyan and Ioannides, 2008), hemodynamic responses (Jäncke et al., 1999; Krumbholz et al., 2007), or intracranial electrophysiological activities (Bidet-Caulet et al., 2007), studies using human participants suggest that the A1 is involved in auditory attention. Particularly, using the method of magnetoencephalography, our recent studies have shown that the human A1 plays a role in integrating both spectral (feature) cues and spatial cues to perceptually segregate co-occurring speech sounds in a complex listening environment (Du et al., 2011). Electrophysiological studies using laboratory animals have also shown that the $\mathrm{A} 1$ is important for mediating attention in rats (Polley et al., 2006; Jaramillo and Zador, 2011), ferrets (Fritz et al., 2007), and cats (Lee and Middlebrooks, 2011). Thus, blocking the A1 may impair both auditory object/ feature-based attention and auditory spatial attention, leading to that attention-impaired rats do not exhibit any attentional modulations of PPI. Moreover, the A1 sends descending axonal projections to some important relay sites in the pathway mediating PPI, including the IC (Herbert et al., 1991; Druga et al., 1997; Coomes et al., 2005; Schofield, 2009), pedunculopontine tegmental nucleus (PPTg), and laterodorsal tegmental nucleus (Schofield and Motts, 2009; Schofield, 2010). Thus, the A1 may directly mediate the top-down modulations of PPI via its direct projections to the PPI pathway. Since blocking the A1 does not have any effects on PPI if the prepulse is not conditioned, the role of the A1 in modulating PPI occurs only when the prepulse stimulus becomes ethologically significant. 


\section{Contributions of the LA}

In this study, the conditioning-induced but not the perceptual separation-induced PPI enhancement was eliminated by reversibly blocking the LA. It is known that the LA is important for the formation of fear conditioning (Romanski and LeDoux, 1992; Pitkänen et al., 1997), suggesting that it is the LA that establishes the association between the conditioned prepulse (CS) and the footshock (US). More importantly, since the amygdala mediates fear-related attention toward the most salient signal, such as a threat, under stressful circumstance (Meck and MacDonald, 2007), and the LA is the critical site for storing memories of the CS-US association (Blair et al., 2005; Schafe et al., 2005), the LA may play a role in retrieving the ecological meanings of the conditioned prepulse and allocating selective attention to the conditioned prepulse that signals a potential threat (the footshock). Thus, blocking the LA may impair expression of the memories of the prepulse-footshock association, and consequently, reduce the rat's attention to the conditioned prepulse. Since blocking the LA abolished conditioning-induced but not perceptual separation-induced PPI enhancement, the LA mainly mediates object/feature-based selective attention to the conditioned prepulse stimulus.

Based on our knowledge, there are two possible pathways for the top-down PPI modulations by amygdala: (1) the amygdala projects to the globus pallidus (Haber et al., 1985), which in turn sends inhibitory projections to the PPTg (Takahashi et al., 2007); (2) the amygdala projects to the deeper layers of the superior colliculus (Meloni and Davis, 2000), another important relay site in the PPI pathway (Fendt et al., 2001). Unlike blocking the A1, blocking the LA reduces the PPI level even when the prepulse is the conditioning-control tone complex, suggesting that the amygdala also provides conditioning-unrelated influences to the PPI pathway.

Since the reduction of the PPI induced by the conditioned prepulse was obviously larger than that of the PPI induced by the conditioning-control prepulse, the PPI reduction after blocking the LA when the prepulse was the conditioned tone complex cannot be explained by a general, conditioning-unrelated function of the LA in modulating PPI.

\section{Contributions of the PPC}

The results of this study also show that blocking the PPC mildly reduced the conditioning-induced PPI enhancement but completely abolished the perceptual separation-induced PPI enhancement, indicating that the PPC specifically contributes to spatial attention to the conditioned prepulse. It is known that, in humans, the PPC plays a role in spatial attention (Kim et al., 1999; Yantis et al., 2002; Greenberg et al., 2010). In rats, it mediates spatial orientation (Reep and Corwin, 2009), attentional setshifting (Fox et al., 2003), long-term memory representation of spatial information (Kesner, 2009), sustained attention against competing distractors (Broussard and Givens, 2010), and incremental processing of conditioned stimuli (Bucci et al., 1998). Anatomically, the rat PPC has reciprocating neural connections with the auditory cortex and the medial prefrontal cortex (Reep et al., 1994), both of which send axonal projections to the amygdala (Romanski and LeDoux, 1993; McDonald et al., 1996). Thus, in the testing environment used in this study, the PPC mainly allocates spatial attention specifically to the conditioned prepulse.

\section{Effects of the conditioning/conditioning-control} manipulation on responses to the startling stimulus alone Consistent with previous reports (Du et al., 2010), the results of this study show that, following the conditioning/conditioningcontrol manipulation (at the procedure stage $\mathrm{AC}$ ), the startle amplitude to the startling stimulus alone became significantly larger in each of the rat groups (Table 1). Within a testing session, the trials with the startling stimulus alone intermixed with both those with the startling stimulus preceded by the conditioned prepulse and those with the startling stimulus preceded by the conditioning-control prepulse. Thus, the enhanced baseline startle response would be associated with sustained fear and/or anxiety without the prepulse specificity (Du et al., 2010). Note that fear-potentiated startle has been traditionally defined as an increase in startle amplitude in the presence versus the absence of the conditioned fear stimulus (i.e., CS) when the CS duration is usually set at a sufficiently long value (e.g., $3700 \mathrm{~ms}$ ) and the CS ending is a few hundred milliseconds behind the offset of the startling stimulus (Kim et al., 1993; Walker and Davis, 1997). Thus, the design of this study was not specifically for investigating fear-induced potentiation of startle.

Moreover, in this study, injection of KYNA into the A1, LA, PPC, or S1BF did not affect the increase of the startle amplitude in the trials with the startling stimulus alone, suggesting that the potentiation of startle following the conditioning/conditioningcontrol manipulation was not mediated by the A1, LA, PPC, or S1BF. The results are generally consistent with the reports in the studies by Kim et al. (1993) and Walker and Davis (1997) showing that, after fear conditioning, the baseline startle amplitude (when only the startling stimulus was presented) was not substantially reduced by either injection of the non-NMDA-receptor antagonist 6-cyano-7-nitroquinoxaline-2,3-dione into the basolateral amygdaloid nuclei (including the LA) (Kim et al., 1993) or injection of the specific AMPA receptor antagonist 2,3dihydroxy-6-nitro-7-sulfamoyl-benzo[f] quinoxaline into one of the three brain regions: the basolateral amygdala, central nucleus of the amygdala, and bed nucleus of the stria terminalis (Walker and Davis, 1997).

\section{New animal models for studying mental disorders}

In patients with schizophrenia, impaired PPI that is induced by the attended prepulse, but not ignored prepulse, is more correlated with the severity of some critical symptoms (Dawson et al., 2000; Braff et al., 2001; Hazlett et al., 2007). However, the correlation between symptoms and PPI deficits cannot be detected in the passiveattention PPI paradigm (Swerdlow et al., 2006). Moreover, in children with attention deficit/hyperactivity disorder (ADHD), PPI induced by attended prepulse is reduced, but it is unaffected if children with ADHD are instructed to ignore the prepulse (Hawk et al., 2002, 2003). Since the impaired attentional modulation of PPI is more correlated with the two disorders than impaired baseline PPI, and particularly, the two disorders have their roots in dysfunctions of the A1 (Javitt et al., 1993; Bekker et al., 2005), the amygdala (Aleman and Kahn, 2005; Serene et al., 2007), and the PPC (Danckert et al., 2004; Curatolo et al., 2009), the top-down modulation of PPI in rats will be useful for establishing new animal models for studying the two mental disorders.

Furthermore, as shown by the results of this study, both the conditioning-induced and perceptual separation-induced PPI enhancements can be completely eliminated by the extinction manipulation. Thus, it is also of interest to know whether the extinction of PPI enhancement involves the forebrain structures, such as the auditory cortex, amygdala, and prefrontal cortex 
(Falls et al., 1992; Quirk et al., 1997; Milad and Quirk, 2002), and the extinction of top-down PPI enhancements in rats also becomes useful for studying posttraumatic stress disorder (PTSD) (Adamec, 1997).

\section{Summary: differentially organized top-down modulations of PPI}

Although the primary pathway that mediates PPI is located in the brainstem (Fendt et al., 2001; Li and Yue, 2002), PPI can be top-down modulated (Li et al., 2009). Previous studies have suggested that multiple forebrain structures are involved in regulating PPI (Bakshi and Geyer, 1998; Miller et al., 2010).

This study, for the first time, provides evidence that the three forebrain structures, A1, LA, and PPC, contribute to the conditioning-induced PPI enhancement and the perceptual separation-induced PPI enhancement differently. We conclude that the neural bases underlying attentional modulations of PPI are differentially organized: The PPC is mainly involved in the spatially attentional modulation, the LA is mainly involved in nonspatially attentional modulation, and the $\mathrm{A} 1$ is involved in both the spatially and nonspatially attentional modulations. Thus, the differentially organized top-down enhancements of PPI refine functions of PPI, making the gating process more flexible to complex environments. In the future, it is important to investigate whether the top-down enhancements of PPI are useful for studying mental disorders, such as schizophrenia, ADHD, and PTSD.

\section{References}

Adamec R (1997) Transmitter systems involved in neural plasticity underlying increased anxiety and defense-implications for understanding anxiety following traumatic stress. Neurosci Biobehav Rev 21:755-765.

Aleman A, Kahn RS (2005) Strange feelings: do amygdala abnormalities dysregulate the emotional brain in schizophrenia? Prog Neurobiol 77:283-298.

Bakshi VP, Geyer MA (1998) Multiple limbic regions mediate the disruption of prepulse inhibition produced in rats by the noncompetitive NMDA antagonist dizocilpine. J Neurosci 18:8394-8401.

Bekker EM, Overtoom CC, Kooij JJ, Buitelaar JK, Verbaten MN, Kenemans JL (2005) Disentangling deficits in adults with attention-deficit/hyperactivity disorder. Arch Gen Psychiatry 62:1129-1136.

Bidet-Caulet A, Fischer C, Besle J, Aguera PE, Giard MH, Bertrand O (2007) Effects of selective attention on the electrophysiological representation of concurrent sounds in the human auditory cortex. J Neurosci 27:9252-9261.

Blair HT, Huynh VK, Vaz VT, Van J, Patel RR, Hiteshi AK, Lee JE, Tarpley JW (2005) Unilateral storage of fear memories by the amygdala. J Neurosci 25:4198-4205.

Braff DL, Geyer MA (1990) Sensorimotor gating and schizophrenia: human and animal model studies. Arch Gen Psychiatry 47:181-188.

Braff DL, Geyer MA, Swerdlow NR (2001) Human studies of prepulse inhibition of startle, normal subjects, patient groups, and pharmacological studies. Psychopharmacology (Berl) 156:234-258.

Broussard JI, Givens B (2010) Low frequency oscillations in rat posterior parietal cortex are differentially activated by cues and distractors. Neurobiol Learn Mem 94:191-198.

Bucci DJ, Holland PC, Gallagher M (1998) Removal of cholinergic input to rat posterior parietal cortex disrupts incremental processing of conditioned stimuli. J Neurosci 18:8038-8046.

Cadenhead KS, Geyer MA, Braff DL (1993) Impaired startle prepulse inhibition and habituation in patients with schizotypal personality disorder. Am J Psychiatry 150:1862-1867.

Carlson S, Willott JF (1996) The behavioral salience of tones as indicated by prepulse inhibition of the startle response: relationship to hearing loss and central neural plasticity in C57BL/6J mice. Hear Res 99:168-175.

Cisler JM, Koster EH (2010) Mechanisms of attentional biases towards threat in anxiety disorders: an integrative review. Clin Psychol Rev 30: 203-216.
Coomes DL, Schofield RM, Schofield BR (2005) Unilateral and bilateral projections from cortical cells to the inferior colliculus in guinea pigs. Brain Res 1042:62-72.

Curatolo P, Paloscia C, D'Agati E, Moavero R, Pasini A (2009) The neurobiology of attention deficit/hyperactivity disorder. Eur J Paediatr Neurol 13:299-304.

Danckert J, Saoud M, Maruff P (2004) Attention, motor control and motor imagery in schizophrenia: implications for the role of the parietal cortex. Schizophr Res 70:241-261.

Davis M, Gendelman PM (1977) Plasticity of the acoustic startle response in the acutely decerebrate rat. J Comp Physiol Psychol 91:549-563.

Dawson ME, Schell AM, Hazlett EA, Nuechterlein KH, Filion DL (2000) On the clinical and cognitive meaning of impaired sensorimotor gating in schizophrenia. Psychiatry Res 96:187-197.

Druga R, Syka J, Rajkowska G (1997) Projections of auditory cortex onto the inferior colliculus in the rat. Physiol Res 46:215-222.

Du Y, Huang Q, Wu X, Galbraith GC, Li L (2009a) Binaural unmasking of frequency-following responses in rat amygdala. J Neurophysiol 101:1647-1659.

Du Y, Li J, Wu X, Li L (2009b) Precedence-effect-induced enhancement of prepulse inhibition in socially reared but not isolation-reared rats. Cogn Affect Behav Neurosci 9:44-58.

Du Y, Ma T, Wang Q, Wu X, Li L (2009c) Two crossed axonal projections contribute to binaural unmasking of frequency-following responses in rat inferior colliculus. Eur J Neurosci 30:1779-1789.

Du Y, Wu X, Li L (2010) Emotional learning enhances stimulus-specific top-down modulation of sensorimotor gating in socially reared rats but not isolation-reared rats. Behav Brain Res 206:192-201.

Du Y, He Y, Ross B, Bardouille T, Wu X, Li L, Alain C (2011) Human auditory cortex activity shows additive effects of spectral and spatial cues during speech segregation. Cereb Cortex 21:698-707.

Falls WA, Miserendino MJ, Davis M (1992) Extinction of fear-potentiated startle-blockade by infusion of an NMDA antagonist into the amygdala. J Neurosci 12:854-863.

Fendt M, Li L, Yeomans JS (2001) Brainstem circuits mediating prepulse inhibition of the startle reflex. Psychopharmacology 156:216-224.

Foss JA, Ison JR, Torre JP Jr, Wansack S (1989) The acoustic startle response and disruption of aiming: I. Effect of stimulus repetition, intensity, and intensity changes. Hum Factors 31:307-318.

Fox JE (1979) Habituation and prestimulus inhibition of auditory startle reflex in decerebrate rats. Physiol Behav 23:291-297.

Fox MT, Barense MD, Baxter MG (2003) Perceptual attentional set-shifting is impaired in rats with neurotoxic lesions of posterior parietal cortex. J Neurosci 23:676-681.

Franklin JC, Moretti NA, Blumenthal TD (2007) Impact of stimulus signalto-noise ratio on prepulse inhibition of acoustic startle. Psychophysiology 44:339-342.

Fritz JB, Elhilali M, Shamma SA (2007) Adaptive changes in cortical receptive fields induced by attention to complex sounds. J Neurophysiol 98:2337-2346.

Fujiwara N, Nagamine T, Imai M, Tanaka T, Shibasaki H (1998) Role of the primary auditory cortex in auditory selective attention studied by wholehead neuromagnetometer. Brain Res Cogn Brain Res 7:99-109.

Graham FK (1975) The more or less startling effects of weak prestimulation. Psychophysiology 12:238-248.

Greenberg AS, Esterman M, Wilson D, Serences JT, Yantis S (2010) Control of spatial and feature-based attention in frontoparietal cortex. J Neurosci 30:14330-14339.

Haber SN, Groenewegen HJ, Grove EA, Nauta WJ (1985) Efferent connections of the ventral pallidum, evidence of a dual striato pallidofugal pathway. J Comp Neurol 235:322-335.

Hawk LW Jr, Redford JS, Baschnagel JS (2002) Influence of a monetary incentive upon attentional modification of short-lead prepulse inhibition and long-lead prepulse facilitation of acoustic startle. Psychophysiology 39:674-677.

Hawk LW Jr, Yartz AR, Pelham WE Jr, Lock TM (2003) The effects of methylphenidate on prepulse inhibition during attended and ignored prestimuli among boys with attention-deficit hyperactivity disorder. Psychopharmacology 165:118-127.

Hazlett EA, Romero MJ, Haznedar MM, New AS, Goldstein KE, Newmark RE, Siever LJ, Buchsbaum MS (2007) Deficient attentional modulation 
of startle eyeblink is associated with symptom severity in the schizophrenia spectrum. Schizophr Res 93:288-295.

Herbert H, Aschoff A, Ostwald J (1991) Topography of projections from the auditory cortex to the inferior colliculus in the rat. J Comp Neurol 304:103-122.

Hoffman HS, Ison JR (1980) Reflex modification in the domain of startle: I. Some empirical findings and their implications for how the nervous system processes sensory input. Psychol Rev 87:175-189.

Hoffman HS, Overman W (1971) Performance disruption by startleeliciting acoustic stimuli. Psychol Sci 24:233-235.

Hoffman HS, Searle JL (1965) Acoustic variables in the modification of starthe reaction in the rat. J Comp Physiol Psychol 60:53-58.

Huang J, Yang Z, Ping J, Liu X, Wu X, Li L (2007) The influence of the perceptual or fear learning on rats' prepulse inhibition induced by changes in the correlation between two spatially separated noise sounds. Hear Res 223:1-10.

Huang Y, Li J, Zou X, Qu T, Wu X, Mao L, Wu Y, Li L (2011) Perceptual fusion tendency of speech sounds. J Cogn Neurosci 23:1003-1014.

Hugdahl K, Law I, Kyllingsbaek S, Brønnick K, Gade A, Paulson OB (2000) Effects of attention on dichotic listening: an ${ }^{15} \mathrm{O}-\mathrm{PET}$ study. Hum Brain Mapp 10:87-97.

Ishii D, Matsuzawa D, Fujita Y, Sutoh C, Ohtsuka H, Matsuda S, Kanahara N, Hashimoto K, Iyo M, Shimizu E (2010) Enhancement of acoustic prepulse inhibition by contextual fear conditioning in mice is maintained even after contextual fear extinction. Prog Neuropsychopharmacol Biol Psychiatry 34:183-188.

Ison JR, Agrawal P, Pak J, Vaughn WJ (1998) Changes in temporal acuity with age and with hearing impairment in the mouse: a study of the acoustic startle reflex and its inhibition by brief decrements in noise level. J Acoust Soc Am 104:1696-1704.

Jäncke L, Mirzazade S, Shah NJ (1999) Attention modulates activity in the primary and the secondary auditory cortex: a functional magnetic resonance imaging study in human subjects. Neurosci Lett 266:125-128.

Jaramillo S, Zador AM (2011) The auditory cortex mediates the perceptual effects of acoustic temporal expectation. Nat Neurosci 14:246-251.

Javitt DC, Doneshka P, Zylberman I, Ritter W, Vaughan HG Jr (1993) Impairment of early cortical processing in schizophrenia - an event-related potential confirmation study. Biol Psychiatry 33:513-519.

Kesner RP (2009) The posterior parietal cortex and long-term memory representation of spatial information. Neurobiol Learn Mem 91:197-206.

Kessler M, Terramani T, Lynch G, Baudry M (1989) A glycine site associated with $N$-methyl-D-aspartic acid receptors: characterization and identification of a new class of antagonists. J Neurochem 52:1319-1328.

Kim M, Campeau S, Falls WA, Davis M (1993) Infusion of the non-NMDA receptor antagonist $\mathrm{CNQX}$ into the amygdala blocks the expression of fear-potentiated startle. Behav Neural Biol 59:5-8.

Kim YH, Gitelman DR, Nobre AC, Parrish TB, LaBar KS, Mesulam MM (1999) The large-scale neural network for spatial attention displays multifunctional overlap but differential asymmetry. Neuroimage 9:269-277.

Koch M (1999) The neurobiology of startle. Prog Neurobiol 59:107-128.

Krumbholz K, Eickhoff SB, Fink GR (2007) Feature- and object-based attentional modulation in the human auditory "where" pathway. J Cogn Neurosci 19:1721-1733.

Landis C, Hunt WA (1939) The startle pattern. New York: Farrar and Rinehart.

Lee CC, Middlebrooks JC (2011) Auditory cortex spatial sensitivity sharpens during task performance. Nat Neurosci 14:108-114.

Li L, Frost BJ (2000) Azimuthal directional sensitivity of prepulse inhibition of the pinna startle reflex in decerebrate rats. Brain Res Bull 51:95-100.

Li L, Kelly JB (1992) Inhibitory influence of the dorsal nucleus of the lateral lemniscus on binaural responses in the rat's inferior colliculus. J Neurosci 12:4530-4539.

Li L, Yue Q (2002) Auditory gating processes and binaural inhibition in the inferior colliculus. Hear Res 168:113-124.

Li L, Korngut LM, Frost BJ, Beninger RJ (1998a) Prepulse inhibition following lesions of the inferior colliculus: prepulse intensity functions. Physiol Behav 65:133-139.

Li L, Priebe RP, Yeomans JS (1998b) Prepulse inhibition of acoustic or trigeminal startle of rats by unilateral electrical stimulation of the inferior colliculus. Behav Neurosci 112:1187-1198.

Li L, Daneman M, Qi JG, Schneider BA (2004) Does the information content of an irrelevant source differentially affect speech recognition in younger and older adults? J Exp Psychol Hum Percept Perform 30:1077-1091.

Li L, Qi JG, He Y, Alain C, Schneider BA (2005) Attribute capture in the precedence effect for long-duration noise sounds. Hear Res 202:235-247.

Li L, Du Y, Li N, Wu X, Wu Y (2009) Top-down modulation of prepulse inhibition the startle reflex in humans and rats. Neurosci Biobehav Rev 33:1157-1167.

Li N, Ping J, Wu R, Wang C, Wu X, Li L (2008) Auditory fear conditioning modulates prepulse inhibition in socially-reared rats and isolation-reared rats. Behav Neurosci 122:107-118.

Litovsky RY, Colburn HS, Yost WA, Guzman SJ (1999) The precedence effect. J Acoust Soc Am 106:1633-1654.

Malmierca MS, Hernández O, Falconi A, Lopez-Poveda EA, Merchán M, Rees A (2003) The commissure of the inferior colliculus shapes frequency response areas in rat: an in vivo study using reversible blockade with microinjection of kynurenic acid. Exp Brain Res 153:522-529.

Maren S (2007) The threatened brain. Science 317:1043-1044.

McDonald AJ, Mascagni F, Guo L (1996) Projections of the medial and lateral prefrontal cortices to the amygdala: a Phaseolus vulgaris leucoagglutinin study in the rat. Neuroscience 71:55-75.

Meck WH, MacDonald CJ (2007) Amygdala inactivation reverses fear's ability to impair divided attention and make time stand still. Behav Neurosci 121:707-720.

Meloni EG, Davis M (2000) GABA in the deep layers of the superior colliculus/mesencephalic reticular formation mediates the enhancement of startle by the dopamine $\mathrm{D}_{1}$ receptor agonist SKF 82958 in rats. J Neurosci 20:5374-5381.

Milad MR, Quirk GJ (2002) Neurons in medial prefrontal cortex signal memory for fear extinction. Nature 420:70-74.

Miller EJ, Saint Marie LR, Breier MR, Swerdlow NR (2010) Pathways from the ventral hippocampus and caudal amygdala to forebrain regions that regulate sensorimotor gating in the rat. Neuroscience 165:601-611.

O'Leary DS, Andreasen NC, Hurtig RR, Torres IJ, Flashman LA, Kesler ML, Arndt SV, Cizadlo TJ, Ponto LL, Watkins GL, Hichwa RD (1997) Auditory and visual attention assessed with PET. Hum Brain Mapp 5:422-436.

Pitkänen A, Savander V, LeDoux JE (1997) Organization of intra-amygdaloid circuitries in the rat: an emerging framework for understanding functions of the amygdala. Trends Neurosci 20:517-523.

Poghosyan V, Ioannides AA (2008) Attention modulates earliest responses in the primary auditory and visual cortices. Neuron 58:802-813.

Polley DB, Steinberg EE, Merzenich MM (2006) Perceptual learning directs auditory cortical map reorganization through top-down influences. J Neurosci 26:4970-4982.

Quirk GJ, Armony JL, LeDoux JE (1997) Fear conditioning enhances different temporal components of tone-evoked spike trains in auditory cortex and lateral amygdala. Neuron 19:613-624.

Reep RL, Corwin JV (2009) Posterior parietal cortex as part of a neural network for directed attention in rats. Neurobiol Learn Mem 91:104-113.

Reep RL, Chandler HC, King V, Corwin JV (1994) Rat posterior parietal cortex-topography of corticocortical and thalamic connections. Exp Brain Res 100:67-84.

Romanski LM, LeDoux JE (1992) Equipotentiality of thalamoamygdala and thalamocorticoamygdala circuits in auditory fear conditioning. J Neurosci 12:4501-4509.

Romanski LM, LeDoux JE (1993) Information cascade from primary auditory cortex to the amygdala: corticocortical and corticoamygdaloid projections of temporal cortex in the rat. Cereb Cortex 3:515-532.

Röskam S, Koch M (2006) Enhanced prepulse inhibition of startle using salient prepulses in rats. Int J Psychophysiol 60:10-14.

Schafe GE, Doyère V, LeDoux JE (2005) Tracking the fear engram: the lateral amygdala is an essential locus of fear memory storage. J Neurosci 25:10010-10015.

Schofield BR (2009) Projections to the inferior colliculus from layer VI cells of auditory cortex. Neuroscience 159:246-258.

Schofield BR (2010) Projections from auditory cortex to midbrain cholinergic neurons that project to the inferior colliculus. Neuroscience 166: 231-240.

Schofield BR, Motts SD (2009) Projections from auditory cortex to cholinergic cells in the midbrain tegmentum of guinea pigs. Brain Res Bull $80: 163-170$

Serene JA, Ashtari M, Szeszko PR, Kumra S (2007) Neuroimaging studies of 
children with serious emotional disturbances: a selective review. Can J Psychiatry 52:135-145.

Stone TW, Connick JH (1985) Quinolinic and other kynurenines in the central nervous system. Neuroscience 15:597-617.

Swartz KJ, During MJ, Freese A, Beal MF (1990) Cerebral synthesis and release of kynurenic acid: an endogeous antagonist of excitatory amino acid receptors. J Neurosci 10:2965-2973.

Swerdlow NR, Keith VA, Braff DL, Geyer MA (1991) Effects of spiperone, raclopride, $\mathrm{SCH} 23390$ and clozapine on apomorphine inhibition of sensorimotor gating of the startle response in the rat. J Pharmacol Exp Ther 256:530-536.

Swerdlow NR, Geyer MA, Braff DL (2001) Neural circuit regulation of prepulse inhibition of startle in the rat, current knowledge and future challenges. Psychopharmacology 156:194-215.

Sverdlow NR, Light GA, Cadenhead KS, Sprock J, Hsieh MH, Braff DL (2006) Startle gating deficits in a large cohort of patients with schizophrenia: relationship to medications, symptoms, neurocognition, and level of function. Arc Gen Psychiatry 63:1325-1335.

Takahashi K, Nagai T, Kamei H, Maeda K, Matsuya T, Arai S, Mizoguchi H, Yoneda Y, Nabeshima T, Takuma K, Yamada K (2007) Neural circuits containing pallidotegmental GABAergic neurons are involved in the prepulse inhibition of the startle reflex in mice. Biol Psychiatry 62:148-157.
Thomson AM, Walker VE, Flynn DM (1989) Glycine enhances NMDAreceptor mediated synaptic potentials in neocortical slices. Nature 338:422-424.

Walker DL, Davis M (1997) Double dissociation between the involvement of the bed nucleus of the stria terminalis and the central nucleus of the amygdala in startle increases produced by conditioned versus unconditioned fear. J Neurosci 17:9375-9383.

Wallach H, Newman EB, Rosenzweig MR (1949) The precedence effect in sound localization. Am J Psychol 62:315-336.

Wang WJ, Wu XH, Li L (2008) The dual-pathway model of auditory signal processing. Neurosci Bull 24:173-182.

Yantis S, Schwarzbach J, Serences JT, Carlson RL, Steinmetz MA, Pekar JJ, Courtney SM (2002) Transient neural activity in human parietal cortex during spatial attention shifts. Nat Neurosci 5:995-1002.

Yeomans JS, Li L, Scott BW, Frankland PW (2002) Tactile, acoustic and vestibular systems sum to elicit the startle reflex. Neurosci Biobehav Rev 26:1-11.

Zou D, Huang J, Wu X, Li L (2007) Metabotropic glutamate subtype 5 receptors modulate fear-conditioning induced enhancement of prepulse inhibition in rats. Neuropharmacology 52:476-486. 